\title{
Attractiveness as a result of having certain personality traits
}

\author{
JAN SPIVEY and WARNER WILSON* \\ University of Alabama, University, Ala. 35486
}

One hundred forty-four undergraduates ranked five persons described by four adjectives, some persons being described by more favorable and some by less favorable adjectives. Half of the questionnaires merely presented the adjectives in an impersonal way; the other half presented the adjectives as personal self-references made by the individuals in question. Favorable vs unfavorable adjectives produced a large effect $(F=788.83$, $\mathrm{df}=4 / 568, \quad \mathrm{p}<.001)$. Personal vs impersonal presentation had no apparent effect $(F=.94$, df $=4 / 258$, n.s.). The results suggest a simple technique for increasing popularity and, possibly, self-esteem.

Can you make a good impression merely by describing yourself as sincere, warm, optimistic, and confident? Past research has determined that some adjectives do make good impressions when they originate from some unspecified source or some unspecified third person and refer to a "hypothetical stranger" (Anderson, 1968; Lott, Lott, Reed, \& Crow, 1970; Rosnow, Wainer, \& Arms, 1969). The authors are not aware of any studies which would indicate whether or not an individual can make a good impression by simply using good adjectives when he describes himself. This research explores this issue by attributing adjectives of various levels of favorability to an impersonal source in some cases and to a personal, that is, first person, source in other cases.

\section{METHOD}

\section{Subjects}

The Ss were 144 University of Alabama undergraduate students of both sexes in a psychology of adjustment course. Participation was worth a small amount of extra credit in their psychology course.

\section{Design}

The study employed 72 Ss in the impersonal group and 72 in the personal, or first person, condition. In the impersonal condition, the Ss read questionnaires which merely presented the adjectives without attributing them to any specific source. In the personal condition, Ss were told that the adjectives were used by five different people in describing themselves. Since each $S$ ranked all five target persons, this was a 2 by 5 design, repeated 72 times. Prior to statistical analysis, the Es converted the five ranks provided by each $\mathrm{S}$ to $\mathrm{T}$ scores, using the table provided by Walker \& Lev (1953, p. 480).

\section{Questionnaire}

The different groups of adjectives, in order of presumed favorability, appear in Table 1.

*The first author carried out the study while enrolled in a directed research course under the direction of the second author.
Table 1

Mean Rank Received by Each Hypothetical Person

\begin{tabular}{lc}
\hline \multicolumn{1}{c}{ Person Descriptions } & Mean Rank \\
\hline Sincere, Warm, Optimistic, Confident & 1.15 \\
Happy, Enthusiastic, Patient, Insecure & 2.27 \\
Friendly, Thoughtful, Pessimistic, Impatient & 2.76 \\
Courteous, Cold, Unenthusiastic, Unhappy & 3.94 \\
Insincere, Unfriendly, Discourteous, Thoughtless & 4.87 \\
\hline
\end{tabular}

The authors composed these lists in order to create five degrees of excellence and relied heavily on the ratings reported by Anderson (1968); however, the authors found it convenient to use several words that were not in Anderson's study.

\section{RESULTS AND DISCUSSION}

The Ss ranked the five persons in the order expected. The mean rankings (possible range, 1-5) appear in Table 1. The tremendous reliability of these rankings is indicated by the analysis of variance reported in Table 2 . The main effect of persons is revealed by an $F$ ratio of almost 800 (vs the ratio of roughly 3 that would have been needed for significance at the .01 level).

This study arose out of an interest in self-presentation as a technique for gaining the esteem of others. It was expected that this study would support others showing that highly favorable third person references make a good impression. It was feared, however, that highly favorable self-references might not make a good impression. If indeed the highly favorable third person references made a good impression and the highly favorable first person references made an unfavorable or less favorable impression, this result would have appeared as a large interaction between the personality descriptions and the personal vs impersonal mode of attribution. In fact, this interaction was .94 , almost exactly chance expectancy. This study, therefore, shows that more favorable adjectives make a significantly better impression, even when they are allegedly applied by a person to himself.

Much past research and common sense testify that some adjectives are more favorable than others. This study again confirms this point. The important thing

Table 2

Analysis of Variance of $T$ Scores

\begin{tabular}{lrc}
\multicolumn{3}{c}{ Analysis of Variance of $\mathbf{T}$ Scores } \\
\hline Source & & \\
\hline Person Description & 4 & $788.83^{*}$ \\
Interaction & 4 & .94 \\
Error Within S & 568 & $(14.99)$ \\
\hline
\end{tabular}

${ }^{*} p<.001$ 
about this study, however, is that it suggests the possibility that knowledge of favorable adjectives may provide a simple technique for selling one's self as well as for praising one's friends. This study leaves it up to further research to determine how well "first person praise" goes over in more intimate face-to-face interactions; it certainly leaves open the possibility, however, that favorable self-presentation may be strategic in many situations. Moreover, if there is anything at all to the old adage of acting one's self into a new way of thinking, first person praise may bolster not only other's esteem but also self-esteem.

\section{REFERENCES}

Anderson, N. H. Likeableness ratings of 555 personality-trait words. Journal of Personality \& Social Psychology, 1968, 9 , 272-279.

Lott, A. J., Lott, B. E., Reed, T., \& Crow, T. Personality-trait descriptions of differentially liked persons. Journal of Personality \& Social Psychology, 1970, 16, 284-290.

Rosnow, R. L., Wainer, H., \& Arms, R. L. Anderson's personality-trait words rated by men and women as a function of stimulus sex. Psychological Reports, 1969, 24, 787-790.

Walker, H. M., \& Lev, J. Statistical inference. New York: Holt, 1953.

(Received for publication January 9, 1973.) 